Article received on August 12 2017

Article accepted on November $13^{\text {th }} 2017$

UDC: 785.1

78.071.1 Поповић Б.

\author{
Srđan Teparić* \\ Department of Music Theory \\ Faculty of Music, Belgrade
}

\title{
TEMPORALITY AND MOVEMENT IN THE COMPOSITION OF TOBA BY BRANKA POPOVIĆ ${ }^{1}$
}

\begin{abstract}
The composition Toba for Symphony Orchestra by Branka Popović, according to the composer's own words, is a piece that "invokes the movement and energy of volcanic activity (...)". Over time it develops as a directed movement, with the reproduction and reduction of texture content. Such a shift of different intensities, realised on a kinetic and colorful plane, leads to the constant flickering of the sections and to the creation of a kind of rhythmic texture that retains the melodic and harmonic musical properties. The movement through music time is always accomplished in the same way: a strong impulse of prolongation leads to an intensified texture movement and accumulation of energy that is released in one instant. Such a concept is disrupted at the moment of the intrusion of a contrasting section in which a circular motion occurs that is caused by the appearance of repetition. Not only will the specifics concerning the perception of music time be considered in this composition, when discussing the principle of the construction of temporality

\footnotetext{
* Author contact information: teparicagmail.com.

1 Sound example is available online at the official New Sound YouTube channel. Please find the playlist here: https://www.youtube.com/watch?v=GZt_2SKutBY\&list=PLNFGwrMs0-Xzo9GYGsuBaxxOc6704_IUJ
} 
and movement. The time flow of the stylistic references of the work neutralised by the appearance of the texture itself indicates the authenticity and the specific stylistic determination of this composition.

Key words: temporality, movement, prolongation, accumulation, resolution, repetition, postmodernism.

\section{Introduction}

The composition Toba for Symphony Orchestra by Branka Popović was written in 2006, in London. It was first performed on 11 February 2017, in the Great Hall of the Kolarac Endowment. The performers were the Symphony Orchestra of Radio Television Serbia, conducted by the Italian conductor Jacopo Sipari de Pescasseroli. The title of the article points to the geographical name of the Indonesian volcanic lake on which the composer comments:

"The Toba Lake in Indonesia is a volcanic lake created by an eruption considered to be the largest that has occurred on Earth in the past 25 million years, with tremendous consequences that were manifested through climatic changes, and even changes in the genetic structure of human beings. The composition invokes the movement and energy of volcanic activity, but it is also inspired by ventures that with their intensity constructively change the spiritual and material environment. It is based on the breakdown of the orchestral set of chord blocks from the end of the Pictures from the Exhibition by Modest Mussorgsky in Maurice Ravel's orchestration."

Indeed, the work points to the eruption of colors set up in the vertical, and expressed through accentuated movement. Ravel's orchestration of the section the Great Gate of Kiev in the composition Pictures from the Exhibition by Modest Mussorgsky, in the Toba composition, has been altered in terms of the sections in it being horizontally displaced in such a way that they do not coincide. The orchestration of the work includes the following instruments: two flutes, three oboes, three clarinets in $b$ flat, two bassoons, four horns in $f$, three trumpets in $\mathrm{b}$ flat, three trombones, tuba and tympana. Percussions are divided into two groups of instruments: suspended cymbal and bass drum, and, vibraphone, snare drum and another suspended cymbal. Ravel's orchestration is very similar, but instead of two, he uses three flutes, and also a contrabassoon and two harps. The composition of the percussion is somewhat different with Ravel, and he uses two timbales, triangles, cymbals, bass drum, tam-tam, bell and timbres. With this instrumental combination, Popović achieves an original form of expressing the orchestration with some kind of colour eruptions indicated by vertical mixing. At the same time, the colours become independent entities that do not intermingle and are vertically separated into multiple entities. All this is accomplished with 
excellent material control and the good use of dynamic contrasts. In accordance with the above mentioned economy, the form of this part has been reworded. Such a framework is the result of intensified movement carried out in waves and through a specific treatment of music time. A unique allegory or musical painting, the composition of Toba by Branka Popović, develops over time as a directed movement through which the textural content is duplicated or reduced. Together with the dynamic changes, this is how the game of constant changes in the intensity of the action is developed so that it can be monitored at the same time on the colour and kinetic plane. In particular, this article will consider the culmination points from two aspects. The first concerns the ways of attaining them, that is, the points of prolongation will be clearly indicated, since they are essential for releasing the built-up energy accumulated in the previous course. The other aspect of the consideration will be about the content that lies within these points and the strategies whereby such spaces are filled. The continuous flickering of the sections that leads to a kind of rhythmic texture, is carried out with compositional procedures that should be separately examined and named. The perception of temporality and movement in the composition Toba by Branka Popović is entirely specific and composed without 'empty spaces'. An analytical look at this composition will be an attempt to review the strategies that have achieved such an outstanding result.

\section{Overview of form}

In the first section of the composition (b. 1-84), a characteristic motif emerges that we might call fanfare. Its potential is also developmental, because at the very beginning, there are two trumpets in $\mathrm{b}$ flat, at a distance of a little second. Characteristic are the incursions of this motif that occur at short intervals, within the horn and trumpet sections. As part of the upper coloured layer of high strings, the characteristic texture is created which represents the basic quality of this composition. (Example 1)

The moving texture is also the basis for creating the musical time of this piece. A comparison could be made with Ligeti's micro-polyphony - with this composer, the moving sound mass, by abolishing traditional music parameters, freezes the music flow, whereas the texture in the composition Toba retains melodic, harmonic, rhythmic and metric properties. A different kind of musical time flow is achieved when a temporary culmination point is reached (b. 30). It involves the long duration of chords in the tutti orchestra. It possesses a diatonic, third ( $f$ a flat) and fourth-fifth potential (b flat e flat), which in a meaningful sense indicates the resolution of the previously established conflict. The orchestration with high tones reserved for brass and woodwind instruments also contributes to the bright sound of this chord. (Example 2) 
Energico $\int-n$

Prata Popovic

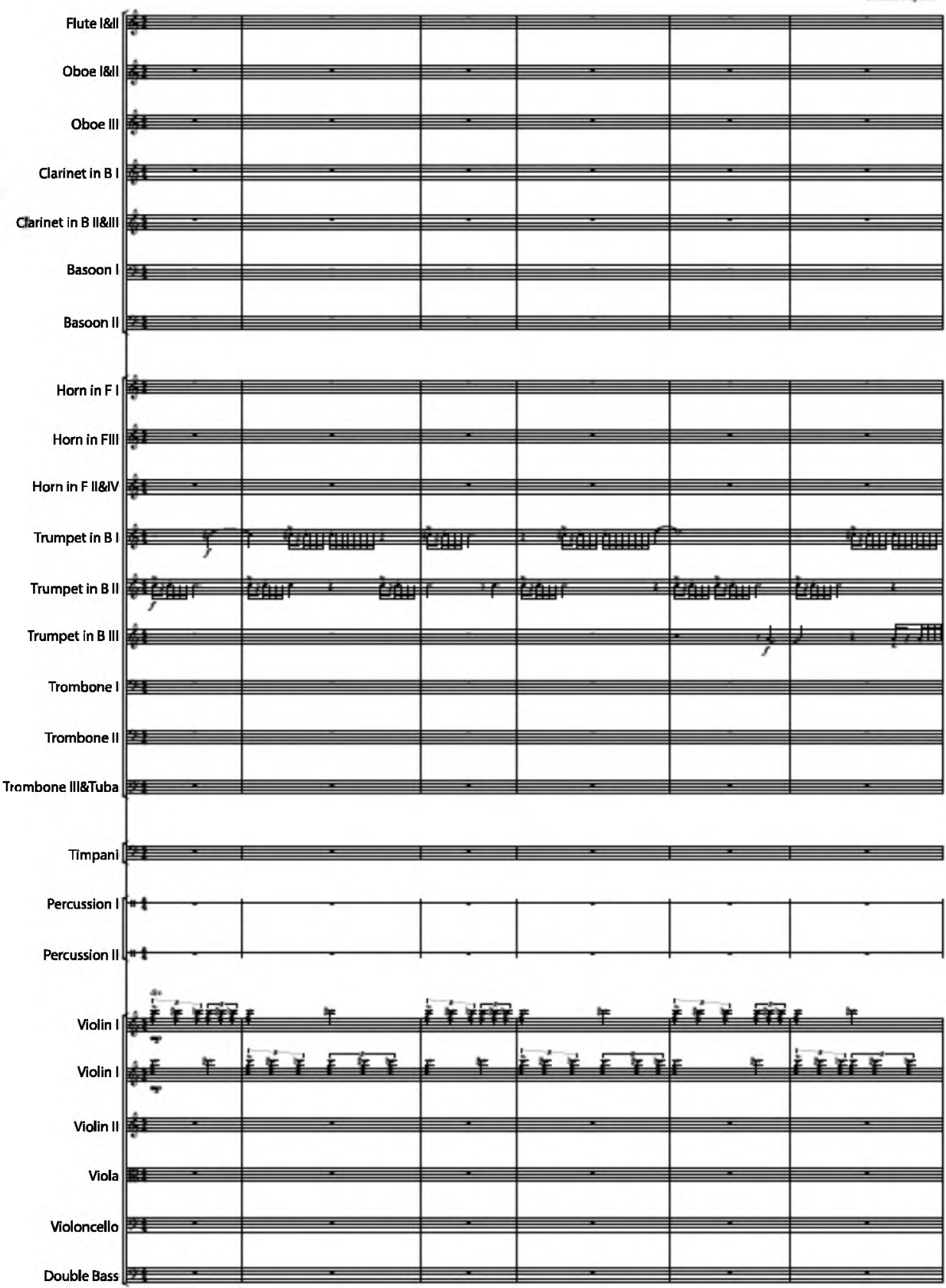

Example 1: Branka Popović, Toba, Fanfare 


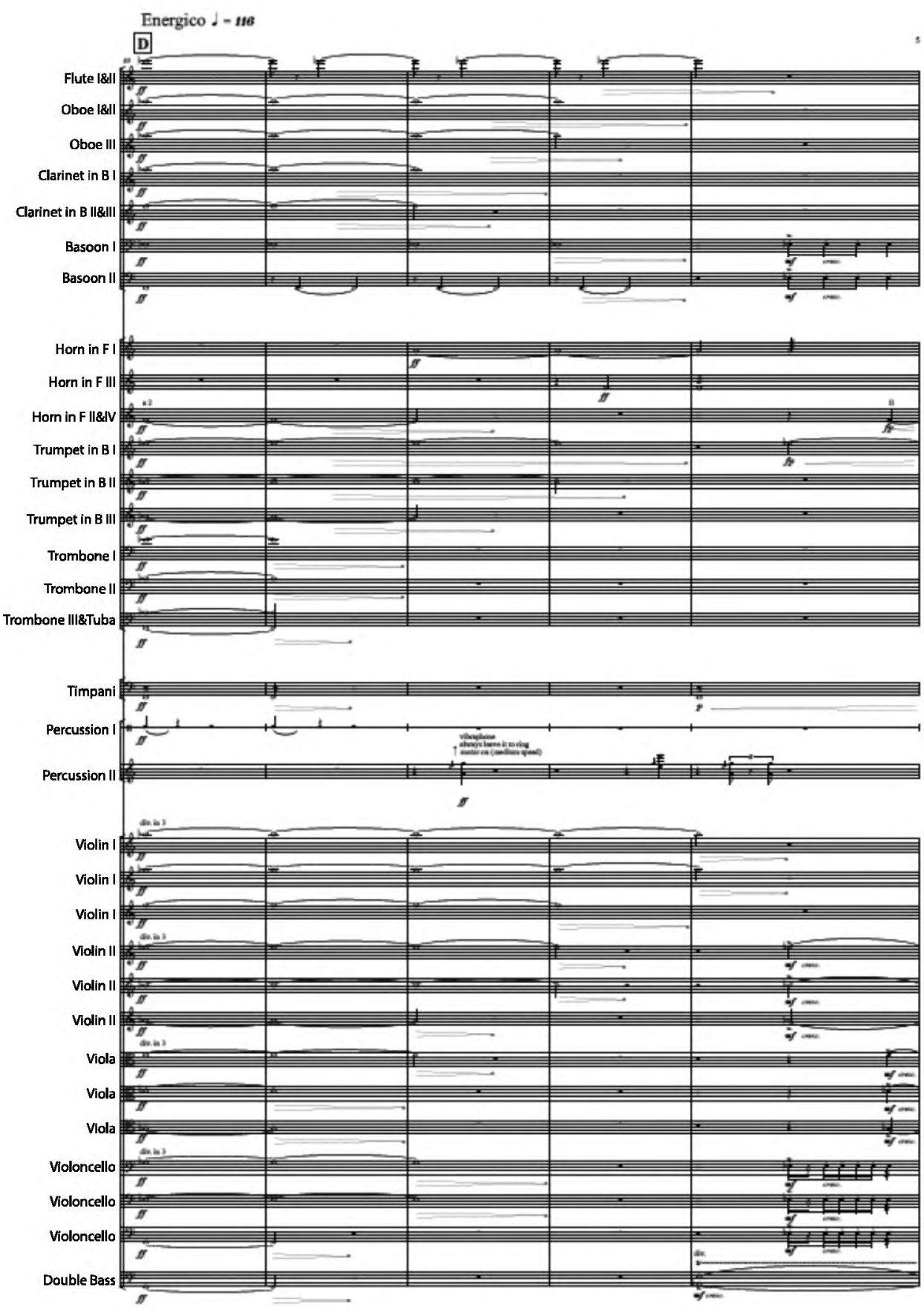

Example 2: Branka Popović, Toba, Lying chords 
At the beginning, in the first section, the composer has already laid the basis for the concept of the whole composition. It is a continuous game of opening and closing, about different levels of the shifting intensity of the texture movement. Such a compositional procedure counts on the neutrality of the references themselves. A fanfare motif could point to a number of different meaningful associations that are related to hunting or war themes, for example. In a given context, however, the meaning is nevertheless rather neutralised. Comparing it with the avant-garde is inevitable, because all the essential musical properties in this case are related to the texture, as one of the important features of the mentioned trend. However, the texture of the Toba composition is more translucent than any texture built on the principle of micro-polyphony, and as we have already said, it enables the expression of the melodic, harmonic and rhythmic content. Consequently, it is also more open to the flow of references, at least in the broadest sense. The avant-garde, modernism, Ravel's method of orchestration, post-minimalist consonance and diatonic, all represent the widest frame, positioned for the flow of musical material. Nevertheless, the whole assembly creates the impression of homogeneity, since each of these references is neutralised in the sense that it is possible to reach their historical origin indirectly. The connection with Romanticism, or perhaps with Impressionism first, lies in the fact that Toba is essentially a composition-picture that displays a certain kind of content. The essential connection with the music of the nineteenth century is reflected in the fact that the very introduction presents two basic materials essential for the formal development of the whole composition. Nevertheless, in the music of Romanticism these would be motifs, and in this case, it is the exspression of two basic principles of creating temporal structures. One is expressed through the strategy of accumulating sound in the texture, and the second one concerns the liberation, that is, the strategy of resolution of the affect, presented by the long-lasting chord echoes.

The second section (b. 85-142) is a continuation of the previous music flow. In it there is a sound stagnation, while the initial fanfare motif, which in the section of the brass wind instruments appears at a distance of a little second, now transformed, appears in the flute section in the form of the shifting high tones at a distance of a minor second ( $f$ and $f$ sharp) and uses a flutter-tonguing technique. This section, in fact, indicates a continuous increase in texture that is quite logical, accompanied by an increase in dynamic values. So gradually, new layers are formed, such as signal tones of the brass. It is material that resembles the initial motif, and this time it appears in the section of string instruments and percussion. 
Q

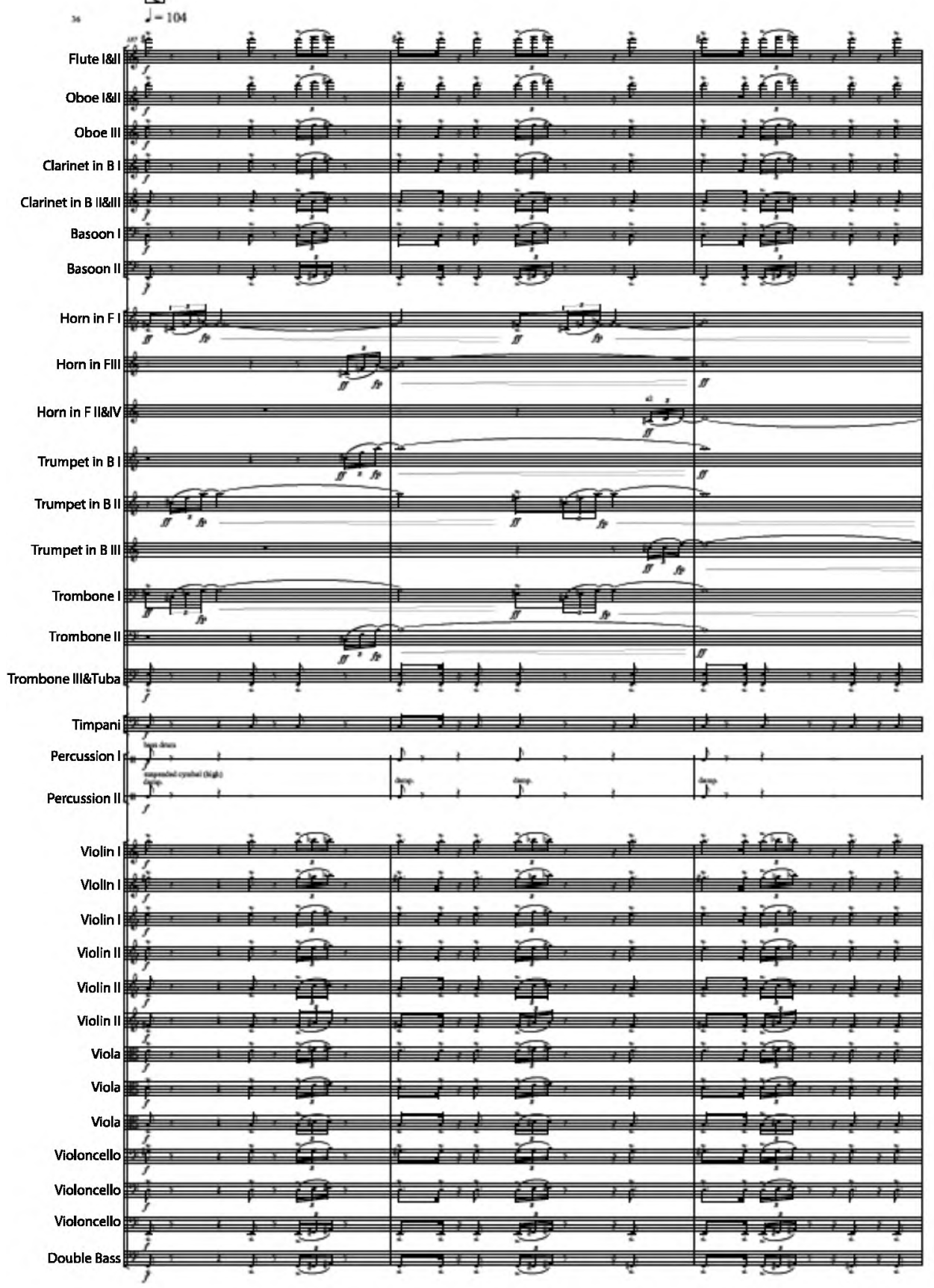

Example 3: Branka Popović, Toba, Rhythmic patterns 
The third section (b. 143-186) does not bring anything new wherein the motifs derived from the initial motif and lying chords change. At its beginning, in the form of a lying consonant chord, the previously accumulated energy is again released.

In the fourth section (b. 187-226), the change of the rhythmic-harmonic model set at the very beginning of the section occurs, which takes place at irregular time intervals. This postminimalistic rhythmic pattern, at the same time, sounds like a pattern of some of the contemporary trends in rock music. It is characteristic of the constant failure of statics achieved by the changing of accents and unequal duration of the model (b. 187-203). In addition to chord strikes, significant changes are made by upward, signal motifs entrusted to the brass instruments. (Example 3)

This contrast section in its second part (b. 204-226), is reduced to strikes only. In this segment of the composition there is a meaningful change, because the moulding of the basic, initial material on postminimalist repetitive models, has the effect of auto-parody. Continuous ups and downs, the opening and closing of the music flow at this point, by the mentioned chord strikes and the particular use of the basic motif, seem to acquire the character of a grotesque. The fifth section (b. 227-275) points to repetition, because in it occurs the initial, fanfare motif. It begins after a two-stroke pause, which is the only real limit in this part, which essentially influences the perception of the flow of the temporal structures and which will be discussed separately.

From the overview itself, it becomes quite clear that one of the main significant frameworks in the Toba composition are the causative and consequential ties resulting from the creation of a field of expectation and its satisfaction. It is created by the accumulation and redundancy of music information, which leads to the temporary resolution of such fields. In addition, there is a third type of creation of temporal structures and it is caused by a kind of surprise effect. This is evident in the appearance of the fourth section, in which there is a significant change. All of the above facts will be specifically considered by the comment on the attached scheme. 


\section{Comment on scheme}

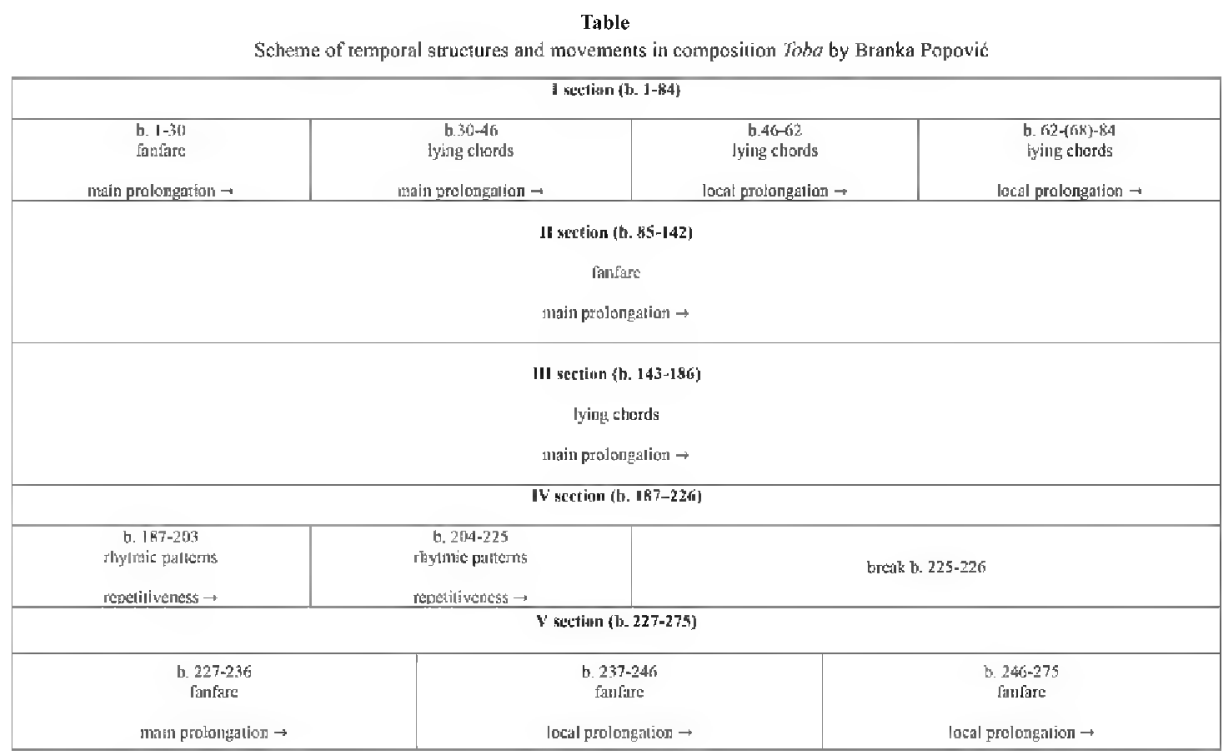

As can be concluded from the accompanying scheme, in the plan of the entire composition, the principle of continuity prevails. As already mentioned, it is interrupted only at one point, by the appearance of the fourth section. After the break of two strokes (b. 225-226), the fifth section follows which is completely based on the replacement of rhythmic models. By embedding this contrasting episode, the prevailing principle of continuity is somewhat distorted, and the return to the familiar materials in the fifth section also indicates the "illusion of reprisal". ${ }^{2}$ The reprise signal is not the same, because, unlike the first section, in the final section only the fanfare motif appears with no prolonged chord durations and with similar but still different orchestral solutions. This way of constructing the form indicates the creation of a balance between the mode of stability and the mode of variability. In other words, the two contradictory principles, in the described way, have been brought to an exceptional degree of interconnectedness. In that sense, it can also be said that in this way, there are also two

2 "Repetition has a special significance for musical form. Although nothing reverses the asymmetry and undirection of time, repetition can create a sense of symmetry and balance within asymmetry and defined shape within anisotropy. Repetitions are not, however, 'real' symmetries, as in spatial forms, but with the one-way movement of time are essentially illusions of symmetry, although most powerful illusions." Barbara R. Barry, Musical Time: The Sense of Order, New York, Pendragon Press, 1990, 66. 
basic types of temporal organisations that merge into a unique and well-organised music time. According to this feature, the music time in the Toba composition completely separates itself from the everyday concept of time, just as in the case of literature, where the story is transmitted from everyday life to the time of fiction. ${ }^{3}$ The aforementioned two principles of temporal organisations also speak of two fundamental criteria, on the basis of which the typology of musical styles is performed, and so we can say that in this case, the classical repetition that points to continuity is brought into balance with a romantic repetition which points to development and growth. ${ }^{4}$

From the scheme it can be noticed that the first and last sections are divided into several phases which we may freely call 'waves', that is, at the content level, they are related to volcanic eruptions. In the first section, there are four such 'waves'. In that sense, we can identify two basic strategies that are obvious at the very beginning and to which the composer adheres consistently. The first is the strategy of prolongation, and it is obvious at the beginnings of all the points marked in the scheme. Each of these prolongations begins in two ways: the first one concerns the second motif (b. 1 and b. 85), which possesses excellent potential for creating a movement.

Another way of creating a prolongation is the movement that begins with the temporary peaks of the composition marked by forte dynamics, a tutti orchestra, and chord echoes. Behind all these culmination points follow cuts of music time in which energy accumulation occurs. The continuous increase in the vertical sound image that leads to the creation of rhythmic texture, therefore, takes place with the strategy of accumulation. In this way, the individual parts are merged into a unified precomposed whole. In explaining the two basic ma-

3 "But if a subjective duration is subjacent to the objective deployment of tone, tha latter subordinates the former to itself, that is to say, to this musical time that its true essence as it is that of music itself. The temporal form of sonority, like its harmonic form, is musical in itself; the same disinterest presides over the perception of both the one and the other: to perceive the time of sonority is for conciousness to detach itself from the practical world of space and of the object and to contemplate its own act in its free power to organise time." Edward A. Lippman, Musical Aesthetics: The twentieth century, New York, Pendragon Press, $1986,342$.

${ }^{4}$ Paraphrased quotes by Mirjana Veselinovic-Hofman, who considers the concepts of rational and psychological temporality, as laid out by Gisèle Brelet. Cf. Мирјана ВеселиновићХофман, Пред музичким делол. Огледи о меһусобним пројекцијала естетике, поетике и стилистике 20. века: једна музиколоика визура [Contemplating the Work of Music on Display - Essays on Mutual Projections of Aesthetics, Poetics, and Stylistics of $20^{\text {th }}$ Century Music: A Musicological Viewpoint], Београд, Завод за уџбенике [Institute for Textbooks], 2007, 131, and, Gisèle Brelet, Essai d'une esthetique nouvelle de la musique, Paris, Presses Universitéres de France, 1949. 
terials at the very beginning, we already said the motif of the fanfare and chord echoes could be compared with the romantic 'piling up' of the basic motifs at the very beginning of the work. This comparison, however, points to a similarity in terms of creating a movement that is related to the content in Romanticism. Thus, the very temporal structure in the mentioned epoch approaches the realisation of real time as a straight linear flow. The temporal structure of the Toba composition is based on strategies for prolongation, accumulation and resolution, with a continuous game of opening and closing time, a game of time flow and its stagnation. In that sense, the music time in this composition was treated as an independent entity in relation to real time. A special case is the fourth section that relates to the previous music flow, at the end of which the music time stops. Within it the mentioned strategies of prolongation and accumulation are omitted. Namely, this section is based on the repetitive repetition of metrically similar patterns. The repetition strategy leads to a circular time flow, different from that generated by the movement of the fanfare motif or the chord echo. Common in all three cases is the movement, which seems to be the basic feature of the entire composition. In many of the above examples, in the Toba composition, we can observe the principle of dualism achieved on many levels: two basic motifs at the outset, two tones at a chromatic distance as the potential for creating prolongation, three unified strategies (accumulation, prolongation and resolution) which, as a common principle, oppose the repetitiveness strategy. The composer's skill is reflected in the skilful handling of all the above-mentioned contradictions and in their inclusion in the unique music time of the composition.

\section{Conclusion}

The method of organising music time, which implies a combination of two opposing strategies, is in line with two basic principles of formal organisation that are also in unity. It is about the principles of continuity and discontinuity, which in the form of the work act uniquely. Possible work references, are neutralised by the appearance of the texture itself, and their time flow points to the meaningful properties that cannot be extracted from the context of the composition itself. In this way, the "timelessness" or, more precisely, the unique temporal structure of the composition comes into being.

Toba is one of the pieces that sublimates stylistic lines and experiences of different orientations. Although it mostly uses the texture, unlike the one in the avant-garde, it is filled with consonant harmonies and appears more airy, which points to minimalist or postminimalist lines. The basic dissonant interval of a small second is reduced to the function of the prolongation agent, while all other 
potentials that were so frequently used in the music of the twentieth century are simply not in use. Possible meaningful connotations, such as the horn signal motif, for example, are completely neutralised in this sense. The serious context of the composition gains its meaningful change by the intrusion of the rhythmic section (fourth section), which in itself carries the potential of the primary playfulness, as is the case in contemporary guitar metal genres. The specific treatment of time and movements in this piece has led to the fact that all references do not act as explicit, but in the overall context they are practically transformed to a degree of neutrality. In this context, the emergence of the subjectivity and expressive authenticity of the composer's 'letter', well-integrated into postmodern stylistic frameworks, is possible.

\section{Works cited}

Barry, Barbara R.: Musical Time: The Sense of Order. New York: Pendragon Press, 1990.

Brelet, Gisèle: Essai d'une esthetique nouvelle de la musique. Paris: Presses Universitéres de France, 1949.

Lippman, Edward A.: Musical Aesthetics: The twentieth century. New York: Pendragon Press, 1986.

Веселиновић-Хофман, Мирјана: Пред музичким делом. Огледи о међусобним пројекиијама естетике, поетике и стилистике 20. века: једна музиколоика визура [Mirjana Veselinović-Hofman: Contemplating the Work of Music on Display - Essays on Mutual Projections of Aesthetics, Poetics, and Stylistics of $20^{\text {th }}$ Century Music: A Musicological Viewpoint]. Београд: Завод за уџбенике [Institute for Textbooks], 2007.

\section{Summary}

The temporal structure of the composition Toba by Branka Popovic is based on strategies for prolongation, accumulation and resolution, with the constant play of opening and closing time, the game of time flow and its stagnation. In that sense, the music time in this composition was treated as an independent entity in relation to real time. A special case is the section that appears before the end of the composition, which relates to the previous music flow. Namely, this section is based on repetitive repetition of similar metric patterns. The repetitiveness strategy leads to a circular time flow, different from that created by the movement of the initial motif, which we call fanfare or chord echoes of dronetones. The composer's skill is reflected in the skilful handling of all the above-mentioned contradictions and in their inclusion in the unique music time of the composition. This way of constructing the form indicates the creation of a balance between the modes of stability and the modes of variability. In other words, the two contradictory principles, in the described way, have been brought to an exceptional degree of interconnection. In that sense, it can also be said that in this way, there are also two basic types of temporal organ- 
isation that merge into a unique and well-organised music time. According to this feature, the music time in the Toba composition completely separates itself from the everyday concept of time, just like the case in literature, where the story from every day life is transmitted to the time of fiction. The fact that this composition differs significantly from postmodernist style citation collages is the fact that the references are completely sublimated in the temporal context of the composition, and are therefore historically neutralised. Although the composition uses the texture to a large extent, it is in this piece, unlike the one in the avant-garde, filled with consonant harmonies and seems more airy, which points to minimalist or postminimalist lines. Modernist dissonance is reduced to some of the basic meaningful connotations, and in this piece it is only a means of creating a prolongation. Ravel's orchestration of the Picture from the Exhibition by Modest Mussorgsky, taken as a reference, has been altered in that sense that all the sections in it are horizontally displaced so that they do not coincide. The specific treatment of time and movement in this piece has led to the fact that all references do not appear to be explicit, but in the overall context, they are practically transformed to a degree of neutrality. In that sense, we can talk about authenticity and a new way of expressing subjectivity, which can stylistically be brought within postmodernist frameworks. 